\title{
Lightness: A Color Marker of Physiological Maturity of Tomato Fruit
}

\author{
Deepak Kumar Jha and Joseph Arul* \\ Department of Food Science and Horticultural Research Center, Laval University, Canada
}

Submission: June 17, 2020; Published: July 02, 2020

"Corresponding author: Joseph Arul, Department of Food Science and Horticultural Research Center, Laval University, Quebec, QC Canada

\begin{abstract}
Harvesting at the physiological maturity is of utmost importance to obtain tomato fruit (Lycopersicon esculentum), which can ripen uniformly and develop flavor. The fruit is picked at mature-green stage for ease of handling and shipping visually aided by USDA Color Chart, but often, immature fruit are also harvested that do not develop full flavor and also presents difficulty at the retail level. Thus, the current investigation was performed to determine the potential of a single-color coordinate, Lightness (L), as a marker in harvesting tomato fruit at mature-green stage. Tomato fruit were harvested based on USDA Color Chart and were further segregated in two groups, based on their Lightness (L) value: one group contained tomato fruit with lightness value of $\mathrm{L}>50$ and the other fruit group had lightness value, $\mathrm{L}<50$. The respiration rate, color change and weight loss were monitored during 4 weeks of storage at $16{ }^{\circ} \mathrm{C}$. The group fruit $(\mathrm{L}<50)$ ripened more uniformly and faster with a lower weight loss, unlike the other fruit group fruit ( $>50)$, which ripened non-uniformly, albeit slowly, with a delay of about 4 days. The former group appeared to have attained maturity, while the latter group were partially mature or somewhat immature at harvest. Results suggest lightness value could be a useful marker of maturity of tomato fruit, and has the potential for use in practice for harvesting tomato fruit at maturity and enable producers to supply fruit that ripens uniformly with more flavor, and reduce the amount of immature fruit being harvested.
\end{abstract}

Keywords: Maturity marker; Reflectance; Cuticular composition; Physiological maturity; Uniformity.

\section{Introduction}

Tomato is the second most consumed fruit/vegetable worldwide and an important dietary source of bioactive compounds such as, dietary fibers, minerals, essential amino acids, vitamin A \& C, carotenoids and phenolics with known health beneficial effects. The consumption of this fruit has been associated with reduced risk of inflammatory processes, cancer, and cardiovascular diseases, diabetes, and obesity. These features make tomato an important horticultural crop worldwide Mulero [1] Van de Poel [2]. However, its highly perishable nature limits its postharvest shelf-life and causes almost $30-35 \%$ postharvest loss worldwide (FAOSTAT 2015).

Harvesting fruits/vegetables at proper physiological maturity stage is of utmost importance for attaining desirable organoleptic quality, since crop maturity impacts the biosynthesis of flavor volatiles Barrett [3]; Beaulieu \& Lea [4], and the selection of postharvest treatments for enhancing storability and value addition Barrett [3], Saad [5]. However, the determination of fruit maturity has been a source of debate over the years Goel \& Sehgal [6]. The identification of tomato fruit maturity is generally performed visually using USDA Color Chart and through field experience. Nevertheless, manual interpretation of maturity being subjective, significant quantities of immature tomato are often harvested as a result and delivered to the retail fresh market Kader [7]. The classification system based on fruit's internal morphology (locular gel content and seed maturity) grouped tomato in four maturity stages: immature, partially mature (pre-mature), mature and advanced mature Kashmire [8]. However, destructive nature of the method limited its use as a tool to distinguish maturity at time of harvest. Hence, finding a rapid, reliable, and non-destructive method to determine fruit maturity is of utmost importance. Near infrared spectroscopy (NIR), a potential non-destructive method, has been extensively explored to determine the quality of ripe tomato fruit Clement [9]; Shao [10]. It was also investigated to determine the chlorophyll content in various maturity stages of the green tomato fruit Tiwari [11]. However, discrepancies in greenness among same maturity stage limited its use as reliable indicator of fruit maturity.

Generally, green-mature stage tomato fruit, being firm, are desired for shipping, handling, and storability. Disparities in the maturity at harvest lead to non-uniformity in ripening and flavor development in a batch of the fruit, and it presents certain operational difficulties at the retail level. What follows 
is a description of the potential use of a single-color coordinate, Lightness (L), as a marker in harvesting tomato fruit at maturegreen stage or sorting fruits at the packing houses to obtain fruits that ripen uniformly.

\section{Materials and methods}

\section{Tomato}

Mature green tomato fruit (Lycopersicon esculentum cv. Starbuck) were harvested manually based on USDA Color Chart from a commercial greenhouse Demers, Levis, QC, Canada. Harvested fruit were of uniform shape, size, color, and free from any infection. The fruit were further segregated based on Lightness (L) in two groups (Group A: L > 50 and Group B: $\mathrm{L}<50$ ). The two fruit groups were placed in plastic containers that maintained a high humidity (RH of 90-95\%), and stored at $16^{\circ} \mathrm{C}$.

\section{Color measurement}

The fruit color coordinate values ( $\mathrm{L}$, a and b) were measured with a colorimeter (Minolta CR200, Osaka, Japan) under typical laboratory light condition on 8 tagged tomato fruit from each group at three pre-marked equidistant locations on the equatorial line on every two days during storage period of $28 \mathrm{~d}$ at $16^{\circ} \mathrm{C}$.

\section{Respiration rate}

The respiration rate $\left(\mathrm{O}_{2}\right.$ depletion and $\mathrm{CO}_{2}$ accumulation $)$ of the fruit was determined by monitoring every hour the headspace gas composition in a closed jar over $3 \mathrm{~h}$ using gas analyzer (Dansensor
CheckMate 3, Mocon Inc., Minneapolis, USA). Measurements were performed in triplicates.

\section{Weight loss}

Weight loss during storage of 8 tagged tomato fruit from each fruit group were measured during $28 \mathrm{~d}$ of storage by recording the weight every other day on a balance (Precisa 180 A, Switzerland) with a precision of $\pm 0.0001 \mathrm{~g}$. Results were expressed as percentage of weight loss.

\section{Results}

\section{Relation between lightness and greenness}

Initially, the color coordinates ( $\mathrm{L}$, a and b) of a batch of 32 harvested mature-green tomato, guided by the visual USDA Color Chart, were measured and the L (lightness) and a (greennessredness) values were related. As seen in Figure 1, the greenness (negative a value) and lightness (L value) showed an inverse linear relationship up to $L$ value of 50 . But above the $L$ value of 50 , the greenness was independent of the $L$ value. The fruit were thus segregated on the basis of $L$ value - a value relationship into two groups: those having $L$ value $<50$ (Group B) and those with L value $>50$ (Group A). The fruit groups were then monitored for climacteric respiration, color change and weight loss to evaluate the homogeneity of ripening during storage. Both groups were subsequently monitored during storage for ripening behavior (color and climacteric respiration) and weight loss.

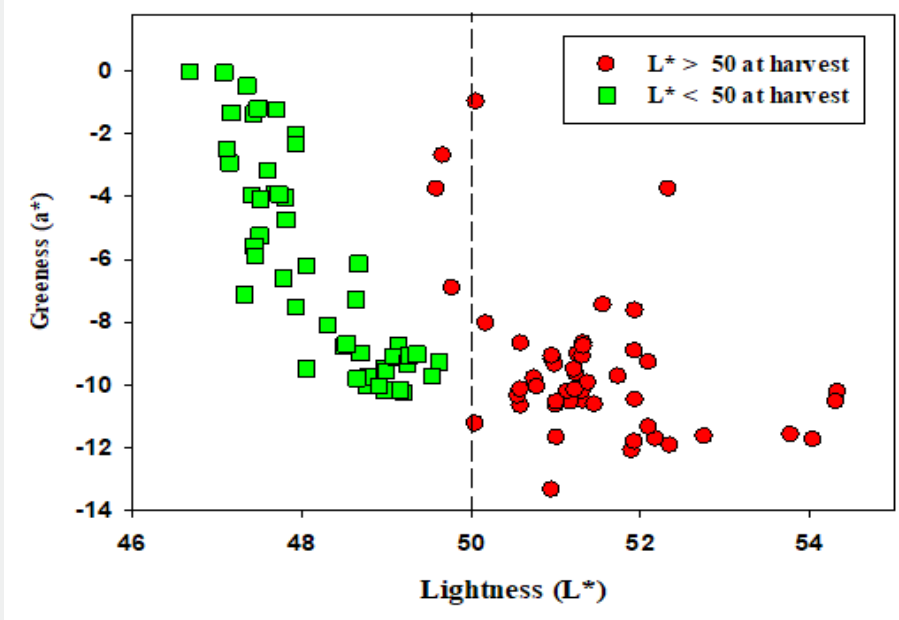

Figure 1: Relation between lightness ( $L$ value) and greenness (-a value) of freshly harvested tomato fruit.

\section{Respiration}

Initial high rate of respiration after harvest was observed in Group A tomato fruit compared to the Group B fruit. However, both tomato fruit groups showed a clear climacteric pattern, where climacteric respiration peaked at day 7 in Group B, and then decreased rapidly Figure 2, and Group A showed a delay of $4 \mathrm{~d}$ in the climacteric peak at day 11. In addition, climacteric respiration rate peak of Group A was lower compared to Group B. 


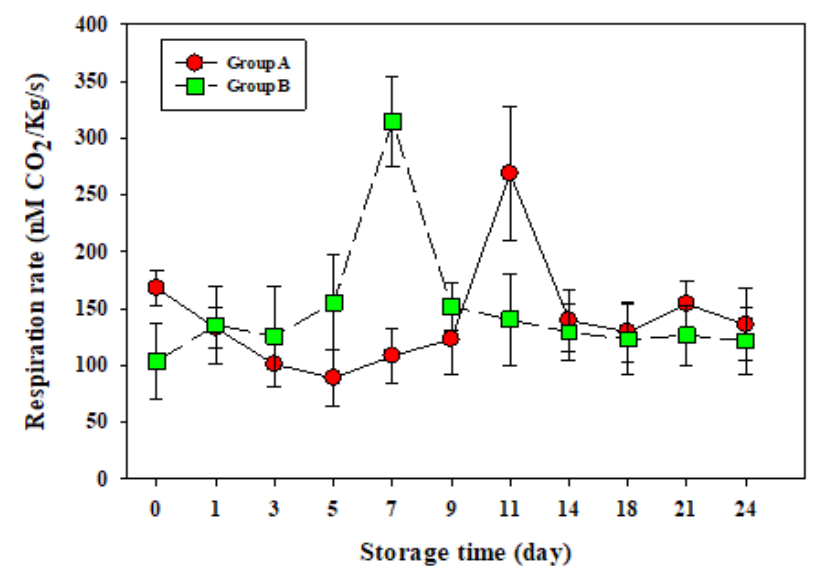

Figure 2: Respiration rate $(R)$ of tomato fruit groups, $A$ and $B$, during storage at $16^{\circ} \mathrm{C}$. A delay in climacteric respiration was observed in immature tomato fruit (Group A).

\section{Color development}

The Group A fruit showed a slower and non-uniform rate of the ripening, whereas it was more uniform in Group B fruit Figure 3. The $\mathrm{L}$ value of both fruit groups decreased with storage time from their initial values, with significant decreases after their respective climacteric, where it remained higher throughout the storage period in Group A fruit than in group B fruit Figure 4A. The ripening of tomato fruit, as judged by redness of the fruit (a value), progressed differently for the two groups during storage Figure 4B. As seen in the climacteric respiration, the ripening of Group B fruit preceded that of Group A fruit, the latter lagging in the progress of ripening by about $4 \mathrm{~d}$. A value reached the value of 20 after 3 weeks of storage in Group B, and after 4 weeks in Group A.

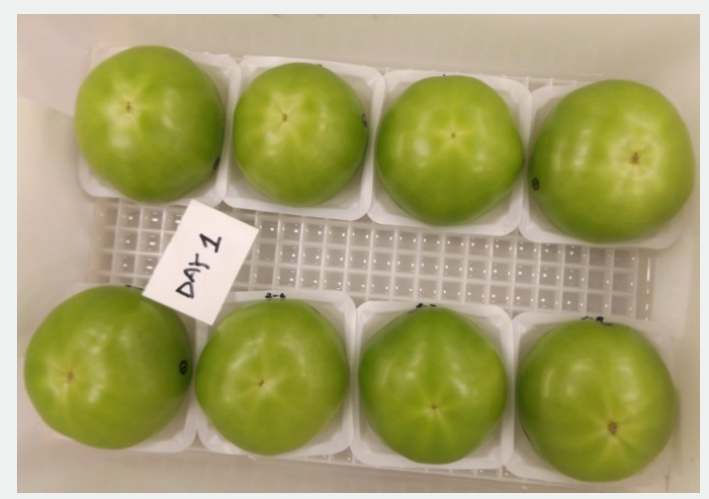

Group A

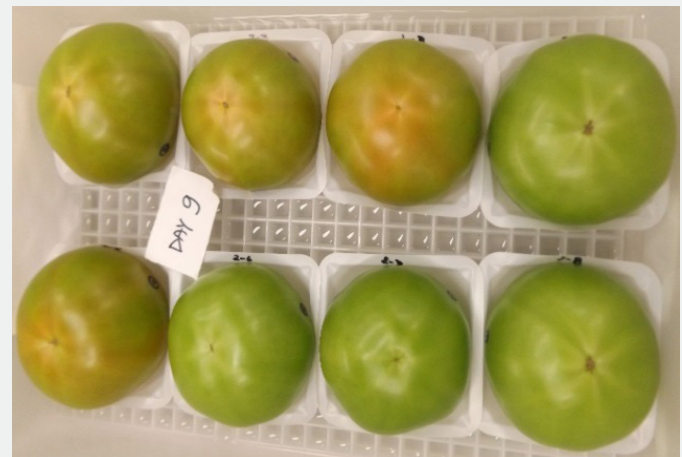

Group A

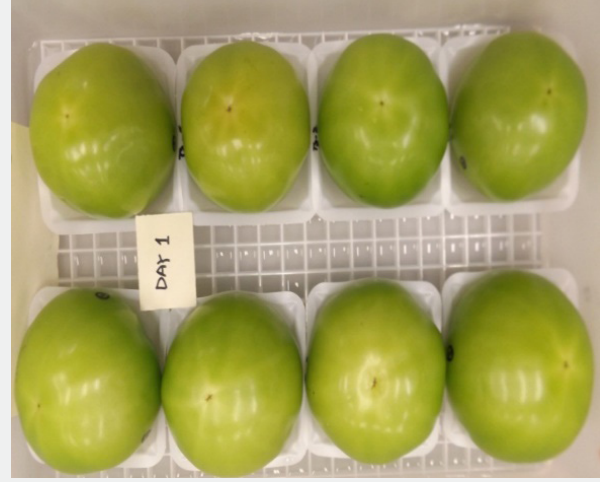

Group B

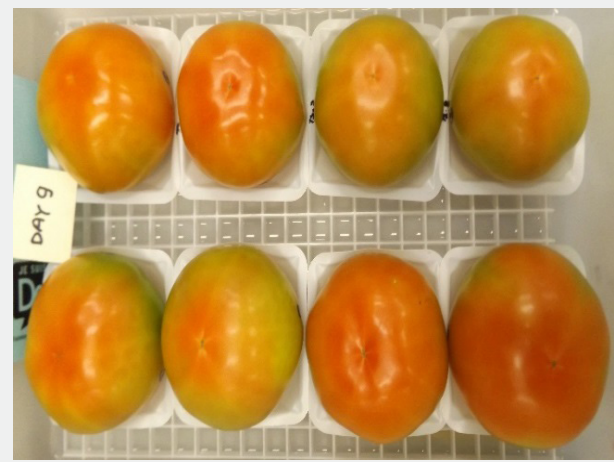

Group B

Figure 3: Color development of tomato fruit groups, $\mathrm{A}$ and B, after $9 \mathrm{~d}$ of storage at $16{ }^{\circ} \mathrm{C}$. 

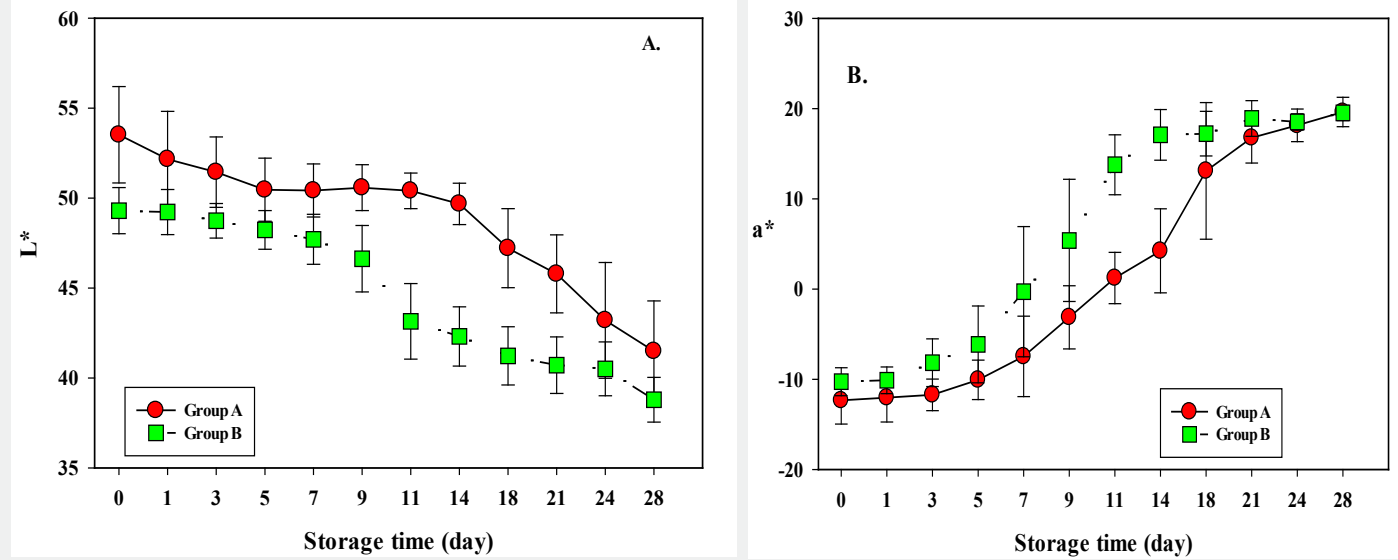

Figure 4: Evolution of Lightness and greenness-redness of tomato groups during storage at $16^{\circ} \mathrm{C}$. A: Lightness (L value) B: Greennessredness (a value).

\section{Weight loss}

Early weight loss in the two fruit groups were not significantly different; but with the onset of ripening (post-climacteric), their weight loss differed significantly between the groups with Group A fruit exhibiting higher weight loss than the Group B fruit Figure 5.

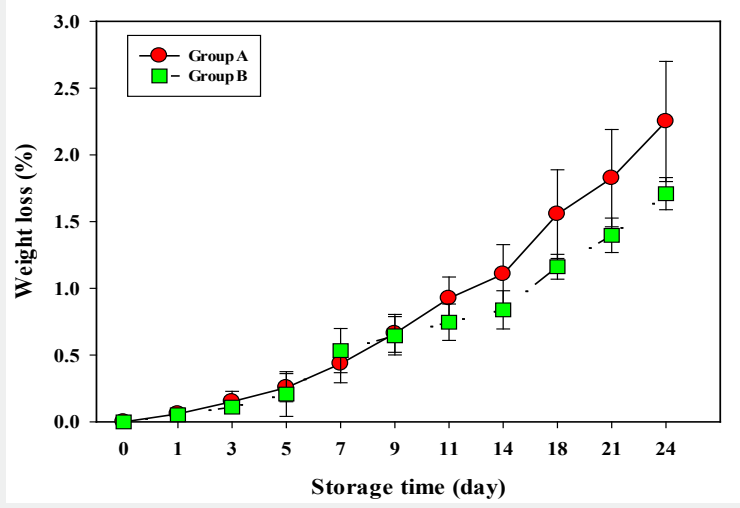

Figure 5: Weight loss of Group A (immature) and Group B (mature) tomato fruits during storage at $16^{\circ} \mathrm{C}$.

\section{Discussion}

Maturity of a fruit is considered as the peak of physiological development, before which fruit are considered immature, and after which fruit are committed to undergo ripening. This transition in the growth stage greatly influences the fruit surface characteristics. The decrease in greenness (negative a value) with the decrease in the L value (lightness, Group B fruit) may indicate a decrease in chlorophyll a/b ratio and an increase in carotenoid to chlorophyll ratio Ecker [12]; and the decrease in L value may indicate a loss in the light reflectance characteristics of the fruit surface due to cuticular wax thinning and restructuring of wax as the fruit matures. Furthermore, the ripening-related cell-wall disassembly and the pigmentation lead to further depletion in $\mathrm{L}$ value and increase in positive a value (redness) Domínguez [13], Liu [14]. Lower values of green color $(a<-10)$ in Group A fruit could be attributed to a higher level of chlorophylls a and $b$ in the epicarp, and initial high rate of respiration after harvest indicating partial photosynthetic nature of tomato fruit that ceases at maturity Lytovchenko [15]. The higher L value of Group A fruit could be attributed to high load of cuticular wax accumulation before reaching maturity, and these fruits were likely harvested before reaching maturity or at somewhat immature stage 
Trivedi [16]. However, the photosynthetic carbon assimilation in immature tomato fruits contribute between $10-15 \%$ of the carbon skeletons required to attain the maximal growth of the fruit, depending on the mother plant Lytovchenko [15]; whereby harvesting even at sub-maturity stage is likely to impel the fruit towards senescence. Thus, it was hypothesized that Group A fruit were not truly mature-green or somewhat immature, while the Group B fruit were of mature-green stage.

The higher value of L in Group A fruit (i.e., immature fruit) might be due to a tightly bound and highly ordered cuticle and epicuticular wax layer effective in reflecting longer wavelengths Holmes \& Keiller [17]. These waxes have considerable structural diversity including layers, crusts, platelets and projections Barthlott [18], which causes higher reflectance. Lower reflectance in Group B (i.e., mature-green fruit) could be due to thinner layer of cuticular wax compared to the immature tomato fruit Becker \& Knoche [19], Lara [20], Liu [14]. It appears that cuticular wax deposition ceases prior to the ripening process as the fruit attains the maximum size, resulting in decreased amounts of cuticular wax per unit surface area, leading to reduced cuticle thickness Liu [14]. The arrested deposition of cuticular components and the associated decline in cuticle thickness causes microcracks as surface strain increases when fruit expands Becker \& Knoche [19], Lara [20], Peschel [21]. These microcracks are eventually filled by restructuring of epi-cuticular waxes, mainly by ester hydrolysis, leading to augmented contents of free fatty acids and the secondary alcohols, which accounts for the glossiness of tomato fruit Lara [20].

\section{Conclusion}

The fruit group having lightness values $<50$ appeared to be at the mature-green stage that exhibited climacteric respiration in about $7 \mathrm{~d}$ after harvest, ripened more uniformly with lower weight loss; whereas the fruit group having lightness values $>50$ bore the attributes of fruit harvested immaturely that they showed initial high respiration rate, delayed climacteric respiration and ripening, unevenness in ripening, and higher weight loss. Since it is of importance from the standpoints of consumer satisfaction and economics to harvest tomato fruit at proper maturity for uniform ripening and fruit flavor development, the color parameter, lightness, could be a reliably used as an indicator of maturity of tomato fruit. Thus, this investigation reveals the values of $\mathrm{L}$ in the range of 50-46 can be used as maturity marker for harvest or sort fruits at the packing houses to obtain fruits with uniform ripening pattern. Further detailed investigation of epicuticular wax composition and its structural diversity at different developmental stages of the fruit would be desirable to establish lightness as a key indicator of tomato fruit maturity.

\section{Acknowledgement}

The authors acknowledge the financial support of Natural Sciences and Engineering Research Council (NSERC), Canada.

\section{References}

1. Mulero J, Abellan J, Zafrilla P, Amores D, Sanchez PH (2015) Bioactive substances with preventive effect in cardiovascular diseases. Nutr Hosp 32(4): 1462-1467.

2. Van De Poel B, Bulens I, Markoula A, Hertog MLATM, Dreesen R, et al (2012) Targeted Systems Biology Profiling of Tomato Fruit Reveals Coordination of the Yang Cycle and a Distinct Regulation of Ethylene Biosynthesis during Postclimacteric Ripening. Plant Physiology 160(3): 1498-1514.

3. Barrett DM, Beaulieu JC, Shewfelt R (2010) Color, flavor, texture, and nutritional quality of fresh-cut fruits and vegetables: desirable levels, instrumental and sensory measurement, and the effects of processing. Crit Rev Food Sci Nutr 50(5): 369-389.

4. Beaulieu JC, Lea JM (2006) Characterization and semiquantitative analysis of volatiles in seedless watermelon varieties using solid-phase microextraction. J Agric Food Chem 54(20): 7789-7793.

5. Saad A, Jha SN, Jaiswal P, Srivastava N, Helyes L (2016) Non-destructive quality monitoring of stored tomatoes using VIS-NIR spectroscopy. Engineering in Agriculture, Environment and Food 9(2): 158-164.

6. Goel N, Sehgal P (2015) Fuzzy classification of pre-harvest tomatoes for ripeness estimation - An approach based on automatic rule learning using decision tree. Applied Soft Computing 36: 45-56.

7. Kader AA, Stevens MA, Albright Holton M, Morris LL, Algazi M (1977) Effect of fruit ripeness when picked on flavor and composition in fresh market tomatoes. Journal of the American Society for Horticultural Science 102: 724-731.

8. Kasmire RF, Kader AA (1978) Handling tomatoes at wholesale and retail: A guide for better quality and greater profits. outlook 5: 5-12.

9. Clement A, Dorais M, Vernon M (2008) Nondestructive measurement of fresh tomato lycopene content and other physicochemical characteristics using visible-NIR spectroscopy. Journal of agricultural and food chemistry 56(2): 9813-9818.

10. Shao Y, He Y, Gómez AH, Pereir AG, Qiu Z, et at. (2007) Visible/near infrared spectrometric technique for nondestructive assessment of tomato 'Heatwave' (Lycopersicum esculentum) quality characteristics. Journal of Food Engineering 81(4): 672-678.

11. Tiwari G, Slaughter DC, Cantwell M (2013) Nondestructive maturity determination in green tomatoes using a handheld visible and near infrared instrument. Postharvest Biology and Technology 86(3): 221229.

12. Ecker JR (2013) Epigenetic trigger for tomato ripening. Nature Biotechnology 31(2): 119-120.

13. Domínguez E, Heredia Guerrero JA, Heredia A (2011) The biophysical design of plant cuticles: an overview. New Phytol 189(4): 938-949.

14. Liu DC, Zeng Q, Ji QX, Liu CF, Liu SB, et al. (2012) A comparison of the ultrastructure and composition of fruits' cuticular wax from the wildtype 'Newhall' navel orange (Citrus sinensis [L.] Osbeck cv. Newhall) and its glossy mutant. Plant Cell Reports 31 2239-2246.

15. Lytovchenko A, Eickmeier I, Pons C, Osorio S, Szecowka M, et at (2011) Tomato fruit photosynthesis is seemingly unimportant in primary metabolism and ripening but plays a considerable role in seed development. Plant Physiology 157(4): 1650-1663.

16. Trivedi P, Nguyen N, Hykkerud AL, Häggman H, Martinussen I, et al (2019) Developmental and Environmental Regulation of Cuticular Wax Biosynthesis in Fleshy Fruits. Front Plant Sci 10: 431.

17. Holmes M, Keiller D (2002) Effects of pubescence and waxes on the reflectance of leaves in the ultraviolet and photosynthetic wavebands: a comparison of a range of species. Plant Cell \& Environment 25: 85-93. 
18. Barthlott W, Neinhuis C, Cutler D, Ditsch F, Meusel I, et al. (1998) Classification and terminology of plant epicuticular waxes. Botanical journal of the Linnean society 126(3): 237-260.

19. Becker T, Knoche M (2012) Deposition, strain, and microcracking of the cuticle in developing 'Riesling'grape berries. Vitis 51: 1-6.
20. Lara I, Belge B, Goulao LF (2014) The fruit cuticle as a modulator of postharvest quality. Postharvest Biology and Technology 87: 103-112.

21. Peschel S, Franke R, Schreiber L, Knoche M (2007) Composition of the cuticle of developing sweet cherry fruit. Phytochemistry 68(7): 10171025.

\section{Your next submission with Juniper Publishers will reach you the below assets}

- Quality Editorial service

- Swift Peer Review

- Reprints availability

- E-prints Service

- Manuscript Podcast for convenient understanding

- Global attainment for your research

- Manuscript accessibility in different formats

( Pdf, E-pub, Full Text, Audio)

- Unceasing customer service

Track the below URL for one-step submission https://juniperpublishers.com/online-submission.php 